\title{
OS PROCESSOS
}

MATERIAIS

EM NOTÍCIAS JORNALÍSTICAS: SELEÇÃO DE PARÂMETROS DESCRITIVOS E ANÁLISE

\section{DE SUAS CORRELAÇÕES}

\section{LOS PROCESOS MATERIALES EN NOTICIAS PERIODÍSTICAS: SELECCIÓN DE PARÁMETROS DESCRIPTIVOS Y ANÁLISIS DE SUS CORRELACIONES}

THE MATERIAL PROCESSES IN JOURNALISTIC NEWS: SELECTING DESCRIPTIVE PARAMETERS AND ANALYZING THEIR CORRELATIONS

\author{
Gesieny Laurett Neves Damasceno* \\ Violeta Virginia Rodrigues** \\ Universidade Federal do Rio de Janeiro
}

RESUMO: Na Gramática Sistêmico-Funcional, a transitividade é concebida como o sistema responsável por codificar as experiências humanas. Baseado nessa perspectiva, este trabalho objetiva identificar as diferentes configurações que processos do tipo material podem assumir em contextos interativos específicos e reconhecer as motivações discursivas para essas codificações. Com vistas a alcançar esses objetivos, selecionamos oito parâmetros descritivos, que permitem analisar, mais sistematicamente, as escolhas efetuadas no âmbito do sistema de transitividade. Além disso, com o intuito de conhecer o grau de interdependência existente entre os fatores linguísticos, estimamos as correlações entre os parâmetros selecionados. O recorte de análise é formado por 131 cláusulas do tipo material, constitutivas de 31 textos pertencentes ao gênero notícia jornalística. A análise dos dados, feita por meio de Mapas Auto-Organizáveis e da estimativa da correlação simples, permitiu entrever, por exemplo, a relação existente entre as expressões metafóricas e a ocultação das entidades agentivas. ${ }^{1}$

PALAVRAS-CHAVE: Processos materiais. Parâmetros descritivos. Mapas Auto-Organizáveis. Estimativas de correlação.

\footnotetext{
* Doutora em Letras Vernáculas/Língua Portuguesa pela Universidade Federal do Rio de Janeiro (UFRJ). E-mail: gesieny@yahoo.com.br

** Professora do Departamento de Letras Vernáculas, Setor de Língua Portuguesa, da Universidade Federal do Rio de Janeiro(UFRJ).E-mail:violetarodrigues@uol.com.br.

${ }^{1}$ Os resultados apresentados aqui integram a tese "A transitividade de processos materiais em notícias jornalísticas", desenvolvida no Programa de Pós-Graduação em Letras Vernáculas da UFRJ.
} 
RESUMEN: En la Gramática Sistémica Funcional, la transitividad está concebida como el sistema responsable por codificar las experiencias humanas. Basado en esa perspectiva, este trabajo objetiva identificar las diferentes configuraciones que procesos del tipo material pueden asumir en contextos interactivos específicos y reconocer las motivaciones discursivas para tales codificaciones. Para alcanzar esos objetivos, seleccionamos ocho parámetros descriptivos, que permiten analizar, más sistemáticamente, las elecciones efectuadas en el ámbito del sistema de transitividad. Además, con la finalidad de conocer el grado de interdependencia existente entre los factores lingüísticos, estimamos las correlaciones entre los parámetros seleccionados. El recorte de análisis está formado por 131 cláusulas del tipo material, constitutivas de 31 textos pertenecientes al género noticia periodística. El análisis de los datos, hecha por medio de los Mapas ‘Auto-organizables’ y de la estimativa de la correlación sencilla, permitió entrever, por ejemplo, la relación existente entre las expresiones metafóricas y la ocultación de las entidades agentes.

PALABRAS CLAVE: Procesos materiales. Parámetros descriptivos. Mapas ‘Auto-organizables’. Estimativas de correlación.

ABSTRACT: The Systemic Functional Grammar defines transitivity as the system responsible for codifying human experiences. Based on such perspective, the aim of the current study is to identify the different configurations that material-type processes may take in specific interactive contexts, as well as to investigate the discursive motivations for such codifications. In order to do so, we have selected eight descriptive parameters that allow making a more systematic analysis of the choices made in the transitivity system. In addition, we have estimated the correlations between the selected parameters in order to understand the degree of interdependence between the linguistic factors. The analyzed clippings comprised 131 material-type clauses from 31 texts belonging to the genre "journalistic news". The data analysis performed through the Self-Organizing Maps and through the estimation of simple correlation, which allowed seeing, for example, the relation between metaphorical expressions and the concealment of agentive entities.

KEYWORDS: Material processes. Descriptive parameters. Self-Organizing Maps. Correlation estimates.

\section{INTRODUÇÃO}

A partir dos pressupostos principais da Gramática Sistêmico-Funcional (GSF) e do status que essa vertente teórica atribui à transitividade na construção dos significados, constituem-se como objetivos principais deste trabalho descrever o modo como o sistema de transitividade dos processos materiais se encontra organizado no contexto das notícias jornalísticas do final do século XX e identificar os sentidos que são construídos por meio dessas representações, considerando-se os propósitos sociocomunicativos do gênero discursivo em questão.

O intuito de analisar, de forma mais sistemática, as configurações do sistema de transitividade em situações específicas de interação levou-nos à seleção de parâmetros descritivos capazes de evidenciar as especificidades desses diferentes modos de realização, tendose em conta tanto aspectos sintáticos quanto aspectos semânticos e pragmático-discursivos. A caracterização dos parâmetros descritivos selecionados e a identificação das relações de interdependência entre esses parâmetros são as propriedades que caracterizam este trabalho.

Os parâmetros descritivos foram selecionados com base nos seguintes critérios: (i) caracterização e diferenciação dos processos transitivos e intransitivos; (ii) identificação do número de participantes presentes na cláusula; (iii) diferenciação dos processos materiais quanto aos quesitos concretude e abstração; (iv) caracterização das diversas faces que os processos de mudança podem assumir (ação, ação-processo e processo); (v) identificação dos papéis semânticos atribuídos à função sintática de sujeito das cláusulas; (vi) reconhecimento das formas de expressão do significado - congruentes, metafóricas ou metonímicas; (vii) identificação de alguns dos objetivos pragmático-discursivos das configurações clausais e (viii) identificação e caracterização dos termos que expandem os significados dos processos materiais - expansão por elaboração, por extensão e por realce.

O recorte de análise deste estudo compreende 131 cláusulas construídas em torno de processos do tipo material. Os processos integram 31 notícias jornalísticas, extraídas do corpus VARPORT. Para o reconhecimento das configurações do sistema de transitividade codificadas nas notícias jornalísticas e a estimativa das correlações entre os parâmetros arrolados, utilizamos como

Damasceno \& Rodrigues | Os processos materiais em notícias jornalísticas: seleção de parâmetros descritivos... 
ferramentas estatísticas os Mapas Auto-Organizáveis (um tipo de modelo de inteligência artificial) e a estimativa da correlação simples.

\section{PRESSUPOSTOS TEÓRICOS - A TRANSITIVIDADE NA GSF}

No quadro teórico da GSF, o sistema de transitividade é a categoria gramatical responsável pela representação das ideias, da experiência humana (metafunção ideacional). Por meio desse sistema, é possível identificar as ações e atitudes humanas retratadas no discurso. Essa identificação se dá através dos papéis principais de transitividade, a saber: os processos, que são os elementos responsáveis por retratar ações e eventos, exprimir ideias e sentimentos, estabelecer relações, construir o dizer e o existir; os participantes, que são os elementos envolvidos com os processos, de forma obrigatória ou não; e as circunstâncias, que correspondem às informações adicionais atribuídas aos diferentes processos.

Os tipos de processo identificados pela GSF são (i) os materiais (processos do fazer e do acontecer); (ii) os mentais (processos que expressam sentimentos, pensamentos e percepções); (iii) os relacionais (processos que estabelecem uma conexão entre entidades, identificando-as ou classificando-as); (iv) os verbais (processos que expressam o dizer); (v) os comportamentais (processos que constroem as ações tipicamente humanas, englobando os comportamentos físico e psicológico) e (vi) os existenciais (processos que representam algo que existe). A cada um desses processos associam-se participantes específicos - determinados pela semântica dos processos - e circunstâncias variadas, que expressam as informações adicionais, mas relevantes para a construção de um domínio particular da experiência.

Nos processos materiais, foco de análise deste trabalho, a fase final, que consiste no resultado do processo, representa alguma mudança de alguma característica do Ator - em uma oração intransitiva - ou da Meta - em uma oração transitiva (HALLIDAY; MATTHIESSEN, 2004, p. 248). O Ator é o participante inerente do processo e é caracterizado como aquele que provoca a ação. Em contrapartida, o participante do tipo Meta é aquele para quem o processo é direcionado, ou seja, aquele que efetivamente é modificado pela ação, como em O leão pegou o turista ${ }^{2}$, em que O Leão é o participante do tipo Ator, e o turista é o participante do tipo Meta.

Além do Ator e da Meta, os processos materiais podem conter outros participantes adicionais, como o Escopo e o Beneficiário. O termo Escopo refere-se ao participante que completa e especifica a ação, mas que não é afetado por ela, como em João tocava piano, em que piano é o Escopo. Já o Beneficiário refere-se à entidade para quem alguma coisa é feita, criada ou transformada, como em $E u$ dei ao meu amor um anel, em que ao meu amor é o participante Beneficiário.

Quanto às circunstâncias, o terceiro componente do sistema de transitividade, estas são responsáveis por delimitar o contexto no qual uma ação acontece. Diferentemente dos participantes, que são definidos pela semântica dos processos, as circunstâncias ocorrem livremente em todos os tipos de processo. As circunstâncias de expansão (extensão e localização), de modo, de causa e de acompanhamento são alguns dos tipos relacionados por Halliday e Matthiessen (2004).

Conforme se percebe, diferentemente da tradicional dicotomia verbos transitivos versus verbos intransitivos, a concepção de transitividade acolhida pela teoria sistêmica é aquela que busca conhecer como as percepções do mundo são organizadas, expressas e entendidas, a partir das escolhas efetuadas no âmbito do léxico e da gramática.

\section{METODOLOGIA}

Nesta investigação, a análise da transitividade encontra-se atrelada à noção de gênero discursivo e, mais especificamente, ao contexto sociocomunicativo das notícias jornalísticas. Dessa feita, para a descrição das configurações dos processos materiais, consideramos 31 textos pertencentes ao gênero notícia jornalística. As notícias, escritas entre os anos 1975 e 2000, foram retiradas do banco de dados do corpus VARPORT.

${ }^{2}$ Os exemplos citados nesta seção são traduções livres de Halliday (1994, p. 109-140) e Halliday e Matthiessen (2004, p. 268-276). 
As escolhas quanto ao banco de dados e ao período histórico dos textos pautaram-se, fundamentalmente, nos seguintes critérios: (i) os dados linguísticos do VARPORT ainda não haviam recebido um tratamento nos termos propostos por este trabalho, e (ii) as notícias, elaboradas no último período compreendido pelo VARPORT (final do século XX), configuram uma fase mais moderna do jornalismo brasileiro, o que faz supor, em termos estruturais, uma relativa aproximação com os textos mais atuais.

A intenção de caracterizar e visualizar, no âmbito do sistema de transitividade, os conteúdos codificados nos textos levou-nos à sistematização de parâmetros descritivos capazes de estabelecer as particularidades existentes entre os processos de natureza material. Assim sendo, com vistas à melhor descrição das cláusulas quanto aos seus aspectos sintáticos, semânticos e pragmáticodiscursivos, pautamos as análises aqui apresentadas em um modelo descritivo formado por oito parâmetros. Além dos fundamentos da GSF, essa seleção considerou o modelo de transitividade elaborado por Hopper e Thompson (1980) e outros pressupostos teóricos, como o conceito de papéis temáticos, de Fillmore (1968), o modelo de divisão verbal de Chafe (1979) e a noção de metonímia, da Linguística Cognitiva (LAKOFF; JOHNSON, 2007).

A seleção dos parâmetros descritivos foi motivada por questões mais abrangentes, que permeiam os estudos que estão sendo realizados acerca do sistema de transitividade (DAMASCENO, 2016). Essas intenções estão voltadas para o reconhecimento das diversas configurações que os processos de modo geral assumem nos contextos particulares de interação e, como não poderia deixar de ser, de suas motivações discursivas. Neste trabalho, focaremos nosso olhar para a caracterização dos parâmetros descritivos, para a averiguação do nível de frequência das classes dos parâmetros nas notícias analisadas e para o estabelecimento das correlações entre essas classes - ou seja, para a identificação do tipo e do grau de interdependência entre um dado linguístico e outro. Os heatmaps, gerados pela Rede Neural de Mapas Auto-Organizáveis, e a correlação simples foram as ferramentas estatísticas empregadas para que esses objetivos fossem mais eficazmente alcançados.

Os Mapas Auto-Organizáveis (do inglês, Self-Organizing Maps - SOM), criados por Kohonen (1982), constituem um tipo de Rede Neural não supervisionada (ou seja, uma rede de inteligência artificial) e representam mais uma das importantes ferramentas disponíveis para organização de dados e informações. O diferencial da Rede Neural de Mapas Auto-Organizáveis (Rede SOM) diz respeito, especialmente, à sua notável característica de representar visualmente a classificação e a distribuição dos dados em mapas topológicos, formados por neurônios.

Como resume Haykin (2001), a Rede SOM é fundamentalmente caracterizada pela formação de um mapa topográfico dos padrões de entrada, no qual as localizações espaciais dos neurônios no mapa são indicativas das características estatísticas intrínsecas contidas nos padrões de entrada (no nosso caso, as cláusulas materiais). Na Rede SOM, os padrões de entrada mais semelhantes são posicionados em neurônios próximos, formando sua vizinhança.

Por meio de aprendizado competitivo, as 131 cláusulas constitutivas do corpus deste estudo foram distribuídas pela Rede SOM sobre o mapa de grade, formado por 121 neurônios (11 x 11). Em virtude dos objetivos pretendidos aqui, estimamos os heatmaps, que visam a demonstrar a representatividade das classes constitutivas dos oitos parâmetros descritivos nas notícias jornalísticas. As análises estatísticas foram realizadas no Programa R versão 3.1.2 (R DEVELOPMENT CORE TEAM, 2011), por meio do pacote "kohonen" (WEHRENS; BUYDENS, 2007).

Além da aplicação da Rede SOM, a análise estatística dos dados foi corroborada pela estimativa da correlação de Pearson (STEEL; TORRIE, 1980). A correlação é uma medida de associação bivariada do grau de relacionamento entre duas variáveis. Esse recurso mensura a direção e o grau dessa relação. As correlações podem variar de zero a 100\%, positiva ou negativamente (estas últimas, marcadas pelo sinal negativo, que indica a direção da relação). A magnitude das correlações aumenta à medida que a estimativa se aproxima de $100 \%$ e $-100 \%$.

\section{CARACTERIZAÇ̃̃O DOS PARÂMETROS DESCRITIVOS E ANÁLISE DE SUAS CORRELAÇÕES}

Nesta seção, caracterizaremos os oito parâmetros selecionados para a descrição do sistema de transitividade de cláusulas materiais e apresentaremos a correlação existente entre as classes que compõem esses parâmetros.

Para as discussões subsequentes, consideremos a Figura 1, a seguir, constituída por heatmaps, ou seja, por mapas topológicos que retratam as classes que compõem os oito parâmetros selecionados.

Damasceno \& Rodrigues | Os processos materiais em notícias jornalísticas: seleção de parâmetros descritivos.. 

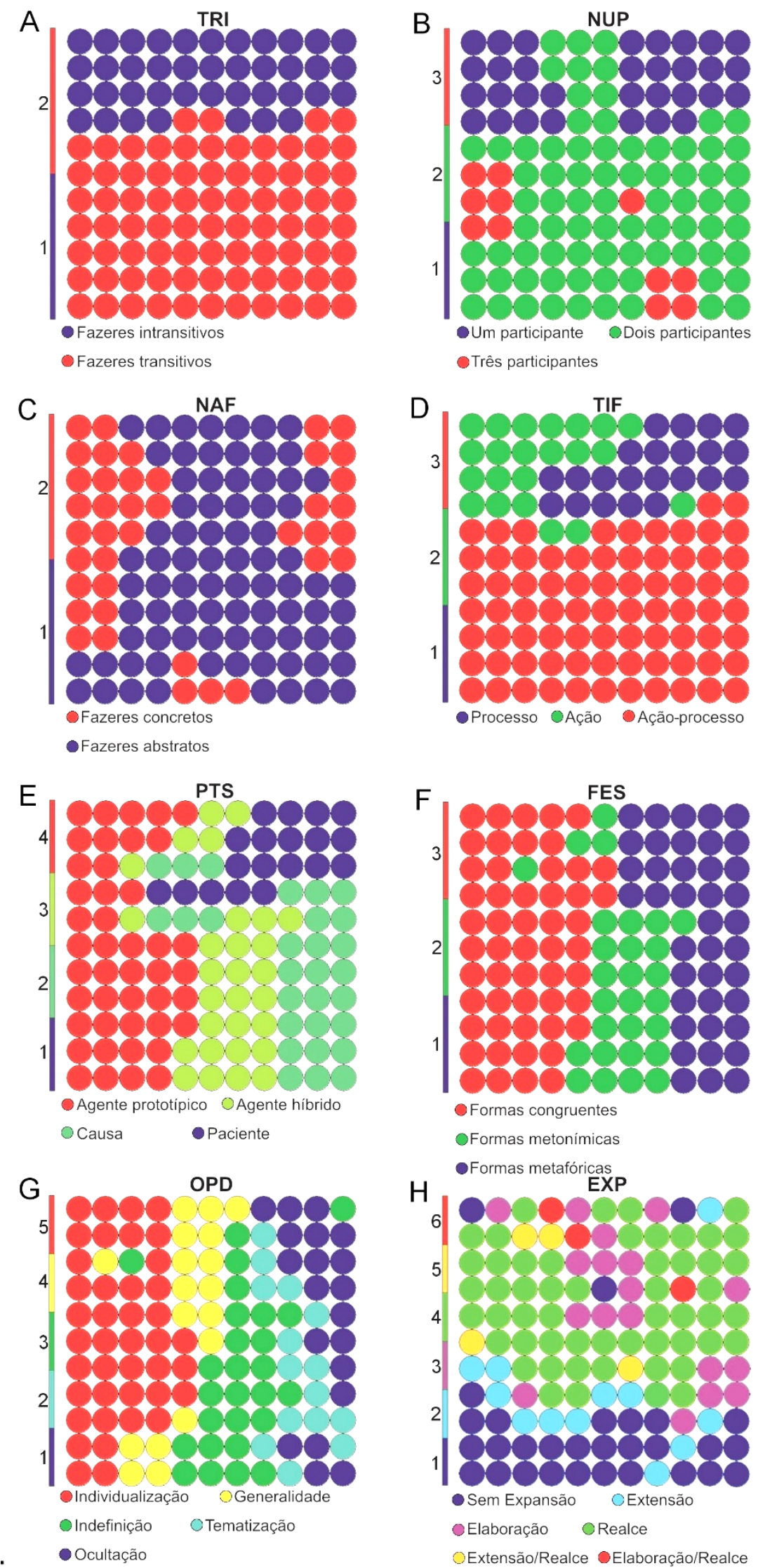

Figura 1: Heatmaps - Representatividade, nas notícias jornalísticas, das classes dos oito parâmetros descritivos (Rede SOM).

Fonte: Produzida pelas autoras

Legenda: TRI - Processos materiais transitivos e intransitivos; NUP - Número de participantes na cláusula; NAF - Natureza dos processos materiais; TIF - Tipos de "fazeres" materiais; PTS - Papel temático do sujeito; FES - Formas de expressão do significado; $O P D$ - Objetivos pragmático-discursivos; EXP - Expansão dos processos materiais. 


\subsection{OS PROCESSOS MATERIAIS TRANSITIVOS E INTRANSITIVOS}

O parâmetro intitulado Processos materiais transitivos e intransitivos objetiva diferenciar uma mudança que se estende a um segundo participante (Meta) de uma mudança que fica confinada ao próprio participante inerente (Ator). As classes definidoras desse parâmetro são: (i) processos transitivos e (ii) processos intransitivos.

De um modo geral, a premissa que subjaz às subcategorizações transitivo e intransitivo na corrente funcionalista de análise linguística é a de mudança (ou afetamento) (HOPPER; THOMPSON, 1980; GIVÓN, 1984). Como parte dessa vertente teórica, para distinguir uma cláusula transitiva de uma intransitiva, a GSF também leva em conta a noção de afetamento, e sua concepção de transitivo/intransitivo se assenta nos seguintes aspectos: (i) somente as cláusulas do tipo material (ou seja, processos do fazer e do acontecer) podem ser subcategorizadas em transitivas ou intransitivas e (ii) a presença de um segundo participante na cláusula (complemento objeto) não é condição suficiente para que esta seja descrita como transitiva.

Acerca do primeiro aspecto, como o que está sendo considerado, em termos de categorização, é a mudança de alguma característica ocorrida entre a fase inicial e a fase final do processo ao longo do tempo, cláusulas construídas com processos mentais, relacionais, verbais, comportamentais e existenciais (como amar, estar, dizer, ouvir e haver) não são descritas como transitivas ou intransitivas. Ações de mudança encontram-se na base conceptual dos processos do tipo material, caracterizados como processos do fazer e do acontecer. Nas cláusulas transitivas, há um participante do tipo Meta, ou seja, um participante efetivamente modificado pela ação. Em contrapartida, as cláusulas intransitivas não possuem esse participante. Os processos caracterizados como transitivos codificam experiências do tipo alguém faz algo a alguém e respondem à pergunta o que $x$ fez a y? Já as construções intransitivas codificam experiências do tipo alguém faz algo e respondem à pergunta o que $x$ fez? Os exemplos listados a seguir, apresentados por Halliday (1994, p. 109), ilustram esse contraste:

[01] Fazer representado por uma cláusula material intransitiva:

$\begin{array}{ll}\text { Oleão } & \text { saltou. } \\ \text { Ator } & \text { Processo }\end{array}$

[02] Fazer representado por uma cláusula material transitiva:

$\begin{array}{lll}\text { Oleão } & \text { agarrou } & \text { oturista } \\ \text { Ator } & \text { Processo } & \text { Meta }\end{array}$

O que se percebe nesses exemplos é que, em ambas as cláusulas, o Ator (realizado pelo grupo nominal O leão) é um participante inerente, e a implicação é que, em ambos os casos, o leão fez algo, ocasionando, portanto, alguma mudança. A diferença que se percebe é que, em [01], o fazer está confinado no leão, enquanto em [02] foi estendido (ou dirigido) ao turista.

Quanto ao segundo quesito, consideremos os seguintes exemplos, retirados de Halliday e Matthiessen (2004, p. 192):

[03] Você estará cruzando algumas montanhas solitariamente, por isso, verifique se você tem gasolina suficiente.

[04] Os meninos estavam jogando futebol.

Em [03] e [04], os termos em destaque (algumas montanhas e futebol) não são afetados (ou modificados) pelo desempenho do processo, por isso não são participantes do tipo Meta, mas do tipo Escopo.

Em contraste ao participante Meta, o Escopo de uma cláusula material não é de forma alguma alterado pelo desenrolar do processo. Pelo contrário, ele interpreta o domínio sobre o qual o processo ocorre (como em [03]), ou, ainda, interpreta o próprio processo, tanto em termos gerais como em específicos (como em [04]). Em ambos os casos, o Escopo é restrito às cláusulas intransitivas, o que significa que uma cláusula material consistindo de 'grupo nominal + grupo verbal + grupo nominal pode ser do tipo 'Ator + Processo + Meta' (transitiva), ou do tipo 'Ator + Processo + Escopo' (intransitiva).

Damasceno \& Rodrigues | Os processos materiais em notícias jornalísticas: seleção de parâmetros descritivos... 
O heatmap do parâmetro Processos materiais transitivos e intransitivos (TRI - Figura 1A) revela que, em termos de frequência, no contexto das notícias jornalísticas, as codificações transitivas apresentaram percentual mais significativo que as intransitivas. A maior ocorrência dos processos transitivos em relação aos intransitivos indica que as experiências retratadas nesses contextos discursivos encontram maior correlação com a configuração o que x fez a y.

Como a organização dos dados sobre o mapa de grade foi feita com base nos oito parâmetros, cumpre verificar de que forma as demais classes arroladas para descrição da transitividade se correlacionam com as classes transitivo/intransitivo. Iniciaremos essa investigação pela correlação existente entre os parâmetros Processos materiais transitivos e intransitivos (TRI) e Número de participantes na cláusula (NUP).

\subsection{NÚMERO DE PARTICIPANTES NA CLÁUSULA}

Por meio do parâmetro Número de participantes na cláusula (NUP), objetivamos identificar a quantidade de participantes envolvidos no processo, a atuação de cada um no desenrolar do evento e as características sintático-semânticas desses participantes. As classes definidoras desse parâmetro são: (i) cláusulas com apenas um participante (Ator); (ii) cláusulas com dois participantes (Ator e Meta, ou Ator e Escopo) e (iii) cláusulas com três participantes (Ator, Meta e Beneficiário).

Dissemos anteriormente que a presença (ou ausência) de um complemento verbal na cláusula material não é tida como condição suficiente para que esta seja dita transitiva (ou intransitiva). No entanto, a correlação existente entre os parâmetros Processos materiais transitivos e intransitivos (TRI) e Número de participantes na cláusula (NUP) revelou-se bastante expressiva, como mostra a Tabela 1 a seguir, em que são apresentadas as estimativas de correlação entre os parâmetros descritivos ${ }^{3}$.

Tabela 1: Estimativas de correlação entre os parâmetros descritivos.

\begin{tabular}{|c|c|c|c|c|c|c|c|c|}
\hline Parâmetros & TRI & NUP & NAP & TIF & PTS & FES & OPD & EXP \\
\hline TRI & $100 \%$ & $80 \%$ & $-32 \%$ & $86 \%$ & $14 \%$ & $-01 \%$ & $-05 \%$ & $-44 \%$ \\
\hline NUP & & $100 \%$ & $-34 \%$ & $76 \%$ & $24 \%$ & $08 \%$ & $05 \%$ & $-27 \%$ \\
\hline NAP & & & $100 \%$ & $-22 \%$ & $20 \%$ & $28 \%$ & $26 \%$ & $18 \%$ \\
\hline TIF & & & & $100 \%$ & $50 \%$ & $18 \%$ & $17 \%$ & $-34 \%$ \\
\hline PTS & & & & & $100 \%$ & $87 \%$ & $83 \%$ & $05 \%$ \\
\hline FES & & & & & & $100 \%$ & $92 \%$ & $12 \%$ \\
\hline OPD & & & & & & & $100 \%$ & $21 \%$ \\
\hline EXP & & & & & & & & $100 \%$ \\
\hline
\end{tabular}

Legenda: TRI - Processos materiais transitivos e intransitivos; NUP - Número de Participantes; NAP - Natureza dos processos materiais; TIF Tipos de "fazeres" materiais; PTS - Papel temático do sujeito; FES - Formas de expressão do significado; OPD - Objetivos pragmático-discursivos; EXP - Expansão dos processos materiais.

Conforme se observa na Tabela 1, a correlação entre os parâmetros Processos materiais transitivos e intransitivos (TRI) e Número de participantes na cláusula (NUP) foi estimada em $80 \%$ (linha 1, coluna 2) - uma correlação positiva e altamente expressiva. Essa correlação se explica pelos seguintes aspectos: (i) ainda que a presença de um complemento verbal não seja condição sine qua non

${ }^{3}$ A Tabela 1 deve ser lida da seguinte forma: a interseção entre uma linha e uma coluna indica a estimativa de correlação entre dois parâmetros. A interseção entre a linha 1 e a coluna 4, por exemplo, indica a correlação estimada entre o parâmetro Processos materiais transitivos e intransitivos (TRI) e o parâmetro Tipos de "fazeres" materiais (TIF). Conforme indicado na Tabela 1, essa correlação é de $86 \%$. 
para que uma cláusula configure um fazer transitivo, na maioria das ocorrências o segundo grupo nominal presente nas construções é do tipo objeto afetado, ou seja, do tipo Meta; (ii) mesmo considerando a premissa de que um fazer intransitivo pode ser construído com um segundo participante (o Escopo), a maioria das ocorrências intransitivas observadas no corpus foi elaborada com apenas um participante. A comparação entre os heatmaps dos parâmetros TRI e NUP (Figuras 1A e 1B) corrobora essas proposições. Tendo como base esses heatmaps, constatamos as seguintes tendências:

(i) Quando TRI é 1 (construções intransitivas, representadas pelos neurônios azuis), NUP tende a também ser 1 (construções com apenas um participante, representadas pelos neurônios azuis).

(ii) Quando TRI é 2 (construções transitivas, representadas pelos neurônios vermelhos), NUP é 2 (construções com dois participantes, representadas pelos neurônios verdes).

(iii) Quando NUP é 3 (construções com três participantes, representadas pelos neurônios vermelhos), TRI é 2 (cláusulas transitivas, representadas pelos neurônios vermelhos).

Esses resultados indicam que, em termos de percentuais, no contexto das notícias jornalísticas, uma cláusula que apresenta um complemento do tipo objeto direto tende a ser mais transitiva que intransitiva, visto que esse segundo participante tende a ser afetado pelo desenrolar do processo. Quanto aos fazeres intransitivos, a forma mais frequente é a que apresenta apenas um participante, aquele que encerra em si mesmo os efeitos de mudança gerados pelo desenrolar da ação.

\subsection{NATUREZA DOS PROCESSOS MATERIAIS}

As cláusulas materiais não expressam, necessariamente, eventos físicos e concretos. Elas podem representar fazeres abstratos, como bem pondera Halliday (1994). Ao parâmetro Natureza dos processos materiais (NAP) compete a discriminação das cláusulas quanto aos critérios concretude e abstração. As classes desse parâmetro são, portanto, (i) fazeres concretos e (ii) fazeres abstratos. Considera-se que os fazeres se encontram no âmbito da abstração quando as mudanças codificadas não podem ser sensorialmente percebidas, como demandam as conceptualizações do tipo mais concretas (RAPOSO et al., 2013, p. 986). Nas cláusulas que compõem este estudo, os fazeres abstratos assumiram esse status por meio dos seguintes artifícios:

(i) o núcleo do sintagma nominal que codifica o participante Ator é do tipo mais abstrato, como o substantivo Regime, que compõe o exemplo [05].

[05] Regime do AI-5 acaba à meia-noite de hoje. (E-B-94-Jn-006)

(ii) O núcleo do sintagma nominal que codifica o participante Meta é do tipo mais abstrato, como a expressão política, do fragmento a seguir.

[06] O Presidente Ernesto Geisel, que governou com o Ato e comandou a política de distensão que o revogou, passa a última noite do ano - e do regime - na Granja do Riacho Fundo. (E-B-94-Jn-006)

Diferentemente do exemplo [05], o participante Ator do exemplo [06] é representado por uma entidade humana, portanto mais concreta (O Presidente Ernesto Geisel). No entanto, o fazer é do tipo mais abstrato pelo fato de o núcleo do sintagma nominal que exerce a função de Meta expressar uma noção mais ideológica, portanto menos concreta.

(iii) Tanto o participante Ator como o participante Meta são codificados por sintagmas nominais cujos núcleos são do tipo mais abstrato. Os substantivos risada e dúvidas, em destaque no exemplo [07], não se referem a entidades que existam por si mesmas, mas a noções abstraídas dos seres humanos, por isso sua natureza é mais abstrata. 
(iv) O próprio predicador selecionado confere ao fazer uma natureza mais abstrata. Consideremos a cláusula seguinte, construída com o verbo massacrar:

[08] No Rio, Lula massacrou Collor com 72,92\% contra 27,08\%. (E-B-94-Jn-021)

Diferentemente dos casos supracitados, no fragmento [08] tanto o participante Ator como o participante Meta foram representados por sintagmas nominais cujas entidades referenciais são animadas e reais - portanto, concretas (Lula e Collor). Todavia, o verbo massacrar foi utilizado em sentido metafórico, o que denotou ao processo uma natureza mais abstrata. A disputa eleitoral entre os candidatos é interpretada pela notícia como uma guerra, e a seleção do predicador massacrar, com implicação modal, enfatiza o altíssimo percentual de votos recebidos pelo candidato Lula, em contraposição ao baixo percentual recebido pelo candidato Collor, no Estado do Rio de Janeiro.

A representatividade dos fazeres concretos e dos fazeres abstratos, disponível na Figura 1C, indica que, no contexto analisado, os fazeres abstratos (neurônios azuis) foram mais recorrentes que os fazeres concretos (neurônios vermelhos). Essa proeminência quantitativa dos fazeres abstratos sobre os fazeres concretos reflete o contexto histórico em que as notícias se encontram atreladas, a saber, um contexto de grande efervescência política, marcado, por exemplo, pelo Movimento Diretas Já (1983), pelo fim do Regime Militar (1985), pela Promulgação da Constituição Federal (1988) e pelo impeachment do presidente Fernando Collor (1992). A quantificação dos dados revelou que $61 \%$ dos assuntos retratados pelas notícias jornalísticas analisadas dizem respeito à esfera política. A maior ocorrência dos processos abstratos justifica-se, portanto, pelo fato dessa temática tratar, fundamentalmente, das relações e dos acordos que são estabelecidos entre os membros da comunidade, valores estes mais situados no campo das ideologias e menos no das percepções sensoriais.

Além dessa constatação, uma análise comparativa entre os heatmaps do parâmetro Natureza dos processos materiais (NAP) e do parâmetro Processos materiais transitivos e intransitivos (TRI) assinala uma relação da seguinte ordem:

(i) a ocorrência maior dos processos abstratos (representados pelos neurônios azuis, de NAP) deu-se nas cláusulas transitivas (representadas pelos neurônios vermelhos, de TRI);

(ii) em contrapartida, em termos proporcionais, as cláusulas intransitivas (representadas pelos neurônios azuis, de TRI) apresentaram maior ocorrência de fazeres concretos (representados pelos neurônios vermelhos, de NAP).

Tendo em vista os heatmaps dos parâmetros NAP e TRI (Figuras 1C e 1A), podemos verificar que, nas notícias analisadas, as cláusulas transitivas codificaram os fazeres mais abstratos, que se encontram atrelados, sobretudo, ao campo das ideias e das relações sociais. Em contrapartida, os fazeres concretos, cujas mudanças são mais perceptíveis aos sentidos, tenderam a ser mais codificados pelas cláusulas intransitivas. As cláusulas exibidas a seguir, construídas com os verbos criar, fugir e viajar, são exemplos, respectivamente, de construções transitivas com um fazer abstrato e de construções intransitivas com fazeres concretos:

[09] Operários da Ford seguem os da Mercedes Benz e criam comissão de salários (E-B-94-Jn-005)

[10] Desde o início do ano, 225 mil alemães-orientais já fugiram para a Alemanha Ocidental. Desses, 50 mil viajaram desde sextafeira, via Tchecoslováquia [...]. (E-B-94-Jn-020)

A Tabela 1, que veicula as estimativas de correlação entre os parâmetros descritivos, revela que a correlação entre os parâmetros Natureza dos processos materiais (NAP) e Processos materiais transitivos e intransitivos (TRI) é de -32\% ${ }^{4}$. Apesar desse número não expressar uma correlação alta, mesmo assim permite vislumbrar que existe uma tendência nos dados analisados, que é a das estruturas linguísticas transitivas expressarem fazeres mais abstratos e dos fazeres concretos serem mais frequentemente codificados por estruturas linguísticas intransitivas (apesar de estas aparecerem em menor quantidade no corpus).

${ }^{4} \mathrm{O}$ sinal negativo indica somente a direção da correlação: quando o valor da classe de um parâmetro sobe, o valor da classe do outro parâmetro tende a descer. 
O parâmetro Tipos de "fazeres" materiais (TIF) objetiva averiguar as diversas configurações que cláusulas do tipo material podem assumir no gênero discursivo em questão e quais sentidos essas formatações evocam na comunicação dos fatos jornalísticos. Como aporte para as discussões apresentadas aqui, tomamos o modelo de divisão verbal sugerido por Chafe (1979) e Borba (1996). Esses autores propõem uma classificação verbal em estado, processo, ação e ação-processo.

Diz-se que o verbo está especificado como estado quando traduz uma visão estática do universo, isto é, tem um núcleo predicativo que não envolve qualquer mudança, como em A madeira está seca. Por sua vez, os verbos de processo expressam um evento ou sucessão de eventos que afetam um sujeito paciente ou experimentador, por isso traduzem sempre um acontecer ou um experimentar, ou seja, algo que se passa com o sujeito ou que ele experimenta - como em A madeira secou, em que o sujeito (sintático) A madeira é paciente, pois o processo de secar o afetou. Já os verbos de ação expressam uma atividade realizada por um agente - indicam, portanto, um fazer por parte do sujeito, como em Miguel correu, em que o nome Miguel especifica o realizador da ação verbal, isto é, seu agente. Por último, os verbos de ação-processo expressam uma ação realizada por um sujeito agentivo (ou causativo), que afeta o complemento, como em Miguel secou a madeira, em que a madeira é o paciente, e Miguel é o agente.

Nas notícias jornalísticas, as cláusulas materiais codificaram mudanças dos tipos processo, ação e ação-processo. Os fragmentos a seguir são exemplos dessas configurações semânticas presentes no corpus. As cláusulas a serem consideradas são aquelas elaboradas com os verbos acabar, entrar e apertar.

[11] Regime do AI-5 acaba à meia-noite de hoje (E-B-94-Jn-006) - processo.

[12] Mohamed Ali Agca, 23 anos, entrou na Itália há duas semanas, vindo da Espanha, desembarcando em Milão. (E-B-94-Jn-012) - ação.

[13] O Papa, com o rosto transtornado pela dor, apertou o abdômen e, em seguida, caiu em cima de seu secretário particular. (E-B94-Jn-012) - ação-processo.

Quanto à frequência, o heatmap do parâmetro Tipos de "fazeres" materiais (Figura 1D) afere que os fazeres do tipo ação-processo foram os mais recorrentes nos dados analisados. Além disso, quando comparamos os heatmaps dos parâmetros Tipos de "fazeres" materiais (TIF) e Processos materiais transitivos e intransitivos (TRI), percebemos que há uma correlação bastante estreita entre as classes representadas nesses dois mapas (Figuras 1D e 1A). Essa correlação, que atingiu o alto percentual de 86\% (Tabela 1), deve ser interpretada da seguinte forma:

(i) Quando TIF é 1 (classe das cláusulas processuais, representada pelos neurônios azuis), TRI tende a ser 1 (classe das cláusulas intransitivas, representada pelos neurônios azuis).

(ii) Quando TIF é 2 (classe das cláusulas de ação, representada pelos neurônios verdes), TRI tende a ser 1 (classe das cláusulas intransitivas, representada pelos neurônios azuis).

(iii) Quando TIF é 3 (classe das cláusulas de ação-processo, representada pelos neurônios vermelhos), TRI tende a ser 2 (classe das cláusulas transitivas, representada pelos neurônios vermelhos).

A relação existente entre esses dois parâmetros chama a atenção especialmente para o fato de, no contexto discursivo analisado, as cláusulas materiais processuais, em sua maioria, serem construções resultantes de uma operação de destransitivização, que integra o sistema de ergatividade. Nas construções ergativas, o sujeito de verbo intransitivo e o objeto de verbo transitivo constituem uma classe, já que apresentam as mesmas características: mesmo comportamento sintático e mesmo conjunto de traços (PEZATTI, 1993). A título de ilustração, consideremos as seguintes relações:

Damasceno \& Rodrigues | Os processos materiais em notícias jornalísticas: seleção de parâmetros descritivos... 
[14] Regime do AI-5 acaba à meia-noite de hoje. (E-B-94-Jn-006)

[14.1] [O Presidente Ernesto Geisel] acaba com o Regime do AI-5 à meia-noite de hoje.

Na estrutura [14], derivada de [14.1], o sujeito agentivo é descartado e o complemento objeto, paciente da construção transitiva, assume a posição de sujeito, conservando, no entanto, a mesma matriz de traços do complemento objeto da estrutura da qual derivou.

Halliday e Matthiessen (2004) explicam que o uso cada vez mais frequente do padrão ergativo no sistema linguístico moderno é parte de uma série de acontecimentos relacionados que foram ocorrendo nas línguas ao longo dos séculos e corresponde a um extenso e complexo processo de mudança semântica. Essas mudanças, segundo os autores, tenderam, como um todo, a enfatizar a função textual na organização do discurso, por comparação à função experiencial; e, dentro da função experiencial, para enfatizar o aspecto de causa-e-efeito do processo, por comparação com o de ação-e-extensão.

Em discussões subsequentes, veremos que o apagamento do SN agente nessas estruturas, em contraste com a total importância dada ao SN afetado, apresenta motivações pragmático-discursivas bastante relevantes nas notícias jornalísticas.

\subsection{A MACROFUNÇÃO ATOR E OS PAPÉIS TEMÁTICOS DO SUJEITO}

Como bem pondera Thompson (1996), os rótulos para os principais participantes envolvidos nos processos materiais são mais facilmente entendidos quando o Ator é uma entidade humana, e a Meta, se houver, é uma entidade inanimada, como em Sua mãe quebrou o vidro. No entanto, o participante Ator pode ser uma entidade inanimada ou abstrata, e a Meta pode, naturalmente, ser uma entidade humana, como em Dezenas de arbustos o arranharam.

Diante dessas constatações, Thompson (1996) chama a atenção para a possibilidade de se identificarem várias subcategorias de processos materiais. Um agrupamento possível seria, por exemplo, separar os processos tendo em conta sua natureza intencional ou involuntária. A cláusula Ela tropeçou no degrau, extraída de Thompson (1996, p. 80), exemplifica este último caso.

A subcategoria dos processos intencionais ou involuntários pode ser mais bem caracterizada a partir da identificação dos papéis temáticos atribuídos ao sujeito das cláusulas. Como as funções de Ator e de sujeito corresponderam, na maioria das estruturas analisadas, ao mesmo sintagma nominal, a identificação dos papéis desempenhados pela categoria sintática de sujeito viabilizou que fossem esmiuçadas as diversas faces da macrofunção Ator nas cláusulas materiais.

A classificação dos componentes linguísticos quanto ao papel semântico que desempenham na cláusula não se constitui, nem de longe, em uma tarefa simples. Por isso, alguns linguistas constantemente têm se debruçado sobre o tema, com vistas a tornar os conceitos mais acessíveis e a elaborar listagens mais abrangentes, de modo que um número maior de casos seja abarcado. Para as análises apresentadas aqui, consideramos os papéis temáticos arrolados por Cançado (2013). Todavia, dado nosso interesse em descrever, de forma mais meticulosa, as escolhas efetuadas pelo usuário da língua, a noção de papéis temáticos adotada neste trabalho considerou essas funções semânticas a partir de uma gradiência. A seguir, listamos os papéis temáticos atribuídos à função de sujeito nas notícias jornalísticas (os casos estão em itálico).

1. Agente prototípico: o Ator é a entidade instigadora da ação. Caracteriza-se por ser [+animada], [+ instigadora] e [+controladora]. Exemplo:

[15] Lula foi logo para o quarto do casal com a Sra. Marisa Letícia da Silva. (E-B-94-Jn-008)

2. Agente 'híbrido': o Ator é a entidade responsabilizada pela ação. No entanto, se caracteriza por ser mais híbrida, ou seja, [+/volitiva] e [+/-controladora]. Exemplo:

[16] A Prefeitura já recuperou os viadutos de Ana Néri e três pontes nas Avenidas Francisco Bicalho e Rodrigues Alves. (E-B-94-Jn$010)$ 
Há quem considere termos como A Prefeitura como locativos alçados à posição de sujeito (HINTZE, 2009). Optamos por considerá-los como integrantes da categoria agentiva por apresentarem a mesma matriz de propriedades sintáticas e semânticas dessa categoria. Entretanto, por entendermos que esse tipo de configuração apresenta peculiaridades no modo como o evento é conceptualizado, visto que se opta por uma expressão metonímica do significado, julgamos por bem, na descrição dos dados, estabelecer uma distinção entre essas construções e as que apresentam um agente prototípico - distinção esta marcada pela gradiência dos atributos volição e controle. Assim, como dissemos anteriormente, essa classe é descrita como sendo [+/-volitiva] e [+/-controladora].

3. Causa: o Ator é a entidade desencadeadora da ação. Caracteriza-se por ser [-animada], [+instigadora] e [-controladora]. Exemplo:

[17] O plano de ajuste anunciado por Collor mexe com virtualmente tudo na vida dos brasileiros. (E-B-94-Jn-022)

4. Paciente: o Ator é a entidade que apenas sofre os resultados do processo. Caracteriza-se por ser [-volitiva], [-controladora], [instigadora]. Exemplo:

[18] Urna eletrônica chega a interior do estado. (E-B-94-Jn-027)

Como vemos, além do papel prototípico de agente ([+animado], [+instigador] e [+controlador]), o participante Ator apresenta características consideradas mais desviantes em relação a esse protótipo.

Quanto à análise estatística dos dados, o heatmap do parâmetro Papel temático do sujeito(PTS), representado na Figura 1E, permite vislumbrar que as cláusulas foram distribuídas pela Rede SOM da seguinte forma:

(i) No lado esquerdo do mapa, representadas pelos neurônios vermelhos, encontram-se reunidas as construções transitivas e intransitivas mais próximas do protótipo das categorias, ou seja, cláusulas cujo participante Ator possui a característica agentiva.

(ii) $\mathrm{Na}$ porção central do mapa, representadas pelos neurônios verde-claros, encontram-se reunidas a maioria das cláusulas transitivas e intransitivas cujo Ator representa um agente híbrido.

(iii) No canto superior direito do mapa, representadas pelos neurônios azuis, encontram-se reunidas a maioria das cláusulas cujo participante Ator possui a característica de paciente, portanto, cláusulas materiais menos prototípicas. Essas construções, por serem do tipo processual, não representam exatamente um fazer, mas sim, um acontecer.

(iv) Nas porções central e inferior do canto direito do heatmap, representadas pelos neurônios verdes, encontram-se reunidas as cláusulas cujo Ator codifica uma causalidade, portanto cláusulas que também se distanciam do protótipo da categoria dos processos materiais transitivos.

Os dados analisados demonstraram uma correlação estatística bastante expressiva entre o parâmetro Papel temático do sujeito (PTS) e os parâmetros Formas de expressão do significado (FES) e Objetivos pragmático-discursivos (OPD), conforme se vê na Tabela 1, citada em seções anteriores. A alta correlação entre esses parâmetros, respectivamente de $87 \%$ e $83 \%$, aponta para o fato, por exemplo, das cláusulas materiais mais periféricas serem fruto de diversificados processos metafóricos, cujos objetivos pragmático-discursivos são bem definidos. A natureza desses processos, como a metáfora da transitividade, e os sentidos por eles pretendidos, como a indeterminação do real agente da ação expressa, serão especificados nas duas próximas seções. 
Como postula a GSF, o que faz da linguagem um sistema semiótico é a ideia subjacente de que os significados são construídos através de escolhas, e que cada escolha adquire um significado em detrimento a outras escolhas que poderiam ter sido feitas. Tendo em vista essa rede de possibilidades, cumpre ao parâmetro Formas de expressão do significado (FES) relacionar o modo como os componentes do sistema de transitividade são articulados nas notícias às funções que esses arranjos desempenham nesse contexto particular de interação.

Nas notícias analisadas, as diferentes relações estabelecidas entre os papéis principais do sistema de transitividade configuraram três importantes formas de expressão do significado. São elas: (i) a forma congruente, (ii) a forma metafórica (metáfora da transitividade) e (iii) a forma metonímica.

A representação congruente, ou menos marcada, é aquela considerada como o modo mais comumente dito em uma determinada língua, ou o modo que é dito na ausência de qualquer circunstância especial (HALLIDAY, 1994). Já a metáfora da transitividade, neste estudo está sendo considerada como o processo em que uma nova expressão de significado surge em função de uma mudança de categoria no interior do sistema léxico-gramatical. Em nosso corpus, foram identificados os seguintes processos metafóricos:

1. Um termo congruentemente circunstancial é estruturado como participante Ator.

2. Um grupo nominal que congruentemente exerce a função de participante Meta nas cláusulas transitivas é estruturado como participante Ator nas cláusulas intransitivas (sistema de ergatividade).

A título de exemplificação, consideremos as seguintes cláusulas, construídas com os verbos restringir e estacionar:

[19] Novas normas restringem grandemente as viagens ao exterior. (E-B-94-Jn-022)

[20] Os tanques israelenses estacionaram ontem a 200 metros do Palácio do Governo do Líbano, anunciou a rádio oficial libanesa. (E-B-94-Jn-014)

No exemplo [19], a configuração da expressão metafórica se deu por meio da utilização de um termo com características circunstanciais na função de Ator do processo (Novas normas). Se considerada em sua expressão mais congruente, teríamos, por exemplo, a seguinte configuração para esse tipo de cláusula:

[19.1] [Alguém] restringe viagens ao exterior por meio de novas normas.

Já no exemplo [20], a significação metafórica ocorreu por meio da codificação de um Ator (Os tanques israelenses) com as típicas características de um participante do tipo Meta, quais sejam: [-volitivo, -instigador e +afetado]. Novamente, se considerada em sua forma mais congruente, teríamos, por exemplo, a seguinte configuração para esse tipo de cláusula:

[20.1] [Alguém] estacionou os tanques israelenses ontem a 200 metros do Palácio do Governo.

Quanto às expressões metonímicas, elas são definidas pelos estudos cognitivistas como "[...] um processo cognitivo em que uma entidade conceitual (o veículo) fornece acesso mental para outra entidade conceitual (o alvo) dentro do mesmo modelo cognitivo idealizado" (RADDEN; KÖVECSES, 1999, p. 21). Essas expressões estiveram presentes no corpus deste estudo nas relações Lugar pela instituição e Instituição pelos responsáveis, conforme preveem Lakoff e Johnson (2007). A seguinte cláusula exemplifica este tipo de configuração:

[21] O Banco Central vai fixar uma nova taxa de câmbio, que se manterá fixa até que o governo entenda ser conveniente outro reajuste. (E-B-94-Jn-016)

No exemplo [21], construído com o verbo fixar, indica-se a instituição financeira (O Banco Central) em vez de se indicarem os nomes dos responsáveis pela fixação da nova taxa de câmbio. 
Em termos de ocorrências, por meio do heatmap do parâmetro Formas de expressão do significado (FES), disponível na Figura 1F, é possível perceber que, apesar das formas congruentes terem sido as mais frequentes, as expressões metafóricas e metonímicas tiveram alta representatividade na elaboração dos significados das notícias jornalísticas.

Quando comparados estatisticamente, os parâmetros Formas de expressão do significado (FES) e Papel temático do sujeito (PTS) apresentaram uma correlação alta, atingindo a marca de 87\% (Tabela 1). Essa correlação pode ser mais bem interpretada através dos heatmaps dos parâmetros FES e PTS (Figuras $1 \mathrm{~F}$ e 1E), a partir dos seguintes aspectos:

(i) quando FES é 3 (forma mais congruente do significado, representada pelos neurônios vermelhos), existe uma forte tendência de PTS ser 4 (papel de agente prototípico, representado pelos neurônios vermelhos).

(ii) Quando FES é 2 (processos metonímicos, representados pelos neurônios verde-escuros), PTS tende a ser 3 (papel de agente híbrido, representado pelos neurônios verde-claros).

(iii) Quando FES é 1 (processos metafóricos, representados pelos neurônios azuis), PTS tende a ser 1 e 2 (papéis de causa e de paciente, representados pelos neurônios verde-escuros e azul-escuros).

A partir dessas correlações, verifica-se que há uma forte tendência das formas congruentes de elaboração do significado apresentarem um sujeito com características agentivas prototípicas. A exceção a essa configuração pode ser vista nas estruturas em que uma forma menos metafórica possui um sujeito paciente individualizado. Nesses casos, conforme já foi mencionado, temos uma construção de processo e não de ação. Em nosso corpus, poucas foram as ocorrências dessa natureza, o que contribuiu para o estabelecimento da alta correlação entre os parâmetros Formas de expressão do significado (FES) e Papel temático do sujeito (PTS). Como exemplo desse tipo de construção menos produtiva, citamos a cláusula construída com o verbo cair, em que o predicador atribui o papel de paciente ao SN individualizado O Papa [João Paulo II]:

[22] O Papa [João Paulo II], com o rosto transtornado pela dor, apertou o abdômen e, em seguida, caiu em cima de seu secretário particular. (E-B-94-Jn-012)

Ainda no que tange às expressões não congruentes, um exame mais sistemático mostrou que a maioria das construções processuais é fruto de rearranjo metafórico. Essa correlação pode ser mais bem observada por meio dos heatmaps dos parâmetros Formas de expressão do significado (FES) e Tipos de "fazeres" materiais (TIF) (Figuras 1F e 1D), que permitem entrever a seguinte analogia: quando FES é 1 (construções metafóricas, representadas pelos neurônios azuis), TIF também tende a ser 1 (construções processuais, representadas pelos neurônios azuis). Essa relação pode ser vista no exemplo [20], comentado em parágrafos anteriores.

\subsection{OBJETIVOS PRAGMÁTICO-DISCURSIVOS DAS CONFIGURAÇÕES CLAUSAIS}

Por meio do parâmetro Objetivos pragmático-discursivos (OPD), objetiva-se evidenciar alguns dos propósitos comunicativos motivadores das estruturas gramaticais. Ao relacionarmos a forma gramatical aos propósitos pragmático-discursivos das notícias jornalísticas, identificamos algumas funções para as configurações das cláusulas materiais. São elas:

1. Individualização do participante inerente: o participante Ator é codificado por SNs com nomes próprios, ou seja, os sintagmas nominais têm como núcleo indivíduos. Nesse tipo de codificação, atesta-se a intencionalidade em expor a pessoa responsável pela ação expressa. Como exemplos, citamos o fragmento a seguir, em que o SN individualizado Sarney é o sujeito agentivo do processo material.

[23] Sarney lança plano da Inflação Zero. (E-B-94-Jn-016)

Damasceno \& Rodrigues | Os processos materiais em notícias jornalísticas: seleção de parâmetros descritivos.. 
2. Generalidade: o Ator é codificado por SNs lexicais genéricos, ou seja, os sintagmas nominais têm como núcleo um substantivo, normalmente acompanhado de um determinante. Os sujeitos agentivos são designados pelo grupo ao qual pertencem, e não de forma individualizada, como nos exemplos anteriores. O objetivo é estender a agentividade à espécie como um todo ou à parte dela, como se observa no exemplo a seguir, em que os indivíduos que compõem o grupo aludido pela expressão Os funcionários públicos se encontram unanimemente comprometidos com o processo, construído com o verbo recuperar:

[24] Os funcionários públicos recuperam o direito de só sofrerem punição de acordo com as leis. (E-B-94-Jn-006)

3. Indefinição do agente: o Ator é representado por SNs lexicais, cujos referentes, na maioria das vezes, são organizações social e legalmente instituídas. Nesse tipo de construção, o real sujeito agentivo é colocado em um plano secundário na comunicação. No exemplo seguinte, a expressão referencial Congresso, representativa das funções de Ator e de sujeito, resguarda a identidade dos deputados e dos ministros responsáveis pela rejeição às eleições diretas para a presidência da república. A ação de rejeição é atribuída, de forma indefinida, à instituição governamental.

[25] Congresso rejeita Diretas. (E-B-94-Jn-015)

4. Ocultação da entidade agentiva: apesar das funções de Ator e de sujeito estarem explicitamente marcadas nesse tipo de representação, não é possível apontar o agente da ação verbal. Nota-se, portanto, a intencionalidade de não expor o instigador do processo de mudança. Como exemplo desse tipo de ocorrência, citamos a cláusula a seguir, construída com o verbo subir, em que o sintagma nominal Passagem de ônibus preenche as funções semântica e sintática de Ator e de sujeito, porém, é parte de uma estratégia discursiva, cujo objetivo é a ocultação dos reais responsáveis pelo aumento da tarifa no Rio de Janeiro.

[26] Passagem de ônibus sobe 50\% no Rio. (E-B-94-Jn-017)

5. Tematização: nesse tipo de estrutura, as funções de Ator, de sujeito e de Tema são compiladas em SNs não agentivos. Todavia, como a entidade instigadora do processo material pode ser recuperada no ambiente textual (diferentemente daquilo que acontece nas codificações mencionadas no item anterior), esses SNs funcionam exclusivamente como a informação mais relevante da cláusula e, ainda, como o ponto de partida para a mensagem a ser veiculada nela. A utilização de tais estruturas é exemplificada no seguinte fragmento de notícia:

[27] Salário mínimo aumenta amanhã. Cruzado substitui o cruzeiro. O Presidente José Sarney, ante a perspectiva de a inflação este ano alcançar 500\%, resolveu aditar medidas de choque que serão anunciadas hoje às $10 \mathrm{~h}$ em cadeia nacional de rádio e televisão. No exemplo [27], o enunciador institui os sintagmas lexicais Salário mínimo e Cruzado como Ator, sujeito e Tema das cláusulas materiais, construídas com os verbos aumentar e substituir. Nesses contextos discursivos, no entanto, a entidade humana responsável pelas ações pode ser identificada no próprio texto, por meio de SNs individualizados, como O Presidente José Sarney.

O heatmap do parâmetro Objetivos pragmático-discursivos (Figura 1G) permite a visualização da frequência, nas notícias jornalísticas, das classes que constituem esse parâmetro: as cláusulas com o agente individualizado foram as mais recorrentes (representadas pelos neurônios vermelhos). Na sequência, apareceram as cláusulas com um agente mais indefinido (representadas pelos neurônios verdes), seguidas pelas cláusulas em que o agente foi ocultado (representadas pelos neurônios azul-escuros) e, por último, com o mesmo número de ocorrências, estiveram as cláusulas que configuram os objetivos tematização (representadas pelos neurônios azul-claros) e generalidade (representadas pelos neurônios amarelos).

A correlação entre os parâmetros Objetivos pragmático-discursivos (OPD) e Formas de expressão do significado (FES) também foi bastante forte, atingindo o percentual de 92\% (Tabela 1). Acerca dessa correlação, os heatmaps dos parâmetros OPD e FES (Figuras $1 \mathrm{G}$ e $1 \mathrm{~F}$ ) assinalam as seguintes tendências:

(i) Quando FES é 3 (forma mais congruente do significado, representada pelos neurônios vermelhos), OPD tende a ser 5 (Individualização, representada pelos neurônios vermelhos). 
(ii) Quando OPD é 3 (Indefinição, representada pelos neurônios verdes), FES tende a ser 2 (forma metonímica do significado, representada pelos neurônios verdes).

(iii) Quando OPD é 1 e 2 (Ocultação e Tematização, representadas pelos neurônios azul-escuros e azul-claros), FES tende a ser 1 (forma mais metafórica do significado, representada pelos neurônios azuis).

A partir dessas tendências, verifica-se que se a maioria das formas mais congruentes de expressão do significado codifica um Ator individualizado, ou seja, se nesse tipo de estrutura expõe-se o indivíduo responsável pela ação, o inverso ocorre com as expressões metonímicas e metafóricas. A análise sistemática dos dados pressupõe que a metonímia e a metáfora da transitividade, no contexto discursivo em questão, revelam-se como recursos muito importantes para os casos em que o que se deseja é a omissão do real agente dos eventos narrados. O uso mais frequente das expressões metafóricas com fins de ocultação do agente corrobora essa proposição.

\subsection{EXPANSÃO DOS PROCESSOS MATERIAIS}

Em adição aos participantes inerentes, há outros papéis participantes e alguns sintagmas circunstanciais que podem estar envolvidos em uma construção do tipo material. Nesta seção, por meio do parâmetro Expansão dos processos materiais (EXP), abarcaremos os termos que expandem o significado das cláusulas materiais. Por questões de limite de espaço, exibiremos somente os tipos de expansão mais produtivos no contexto das notícias jornalísticas.

A teoria sistêmica identifica três relações lógico-semânticas de expansão de uma cláusula material: a elaboração, a extensão e o realce (HALLIDAY; MATTHIESSEN, 2004). Na elaboração, um termo expande o significado de outro, especificando-o, comentando-o, reformulando-o, ou ainda, apresentando exemplos. Já na extensão, um termo expande o significado da cláusula material adicionando a esta algum elemento novo. $\mathrm{Na}$ expansão por realce, um termo realça o significado do processo, fornecendo características circunstanciais de tempo, lugar, causa ou condição.

Nas notícias jornalísticas analisadas, a expansão do tipo Escopo (Entidade) foi a mais frequente expansão por elaboração (com nove ocorrências). Esse tipo de expansão pode ser visto na estrutura seguinte, em que o complemento do verbo seguir (os [operários] da Mercedes Benz) especifica a extensão do processo, mas não é modificado por ele.

[28] Operários da Ford seguem os da Mercedes Benz e criam comissão de salários. (E-B-94-Jn-005)

Quanto à elaboração por extensão, a presença do participante adicional do tipo Beneficiário foi a mais recorrente (também com nove ocorrências). No fragmento [29] a seguir, a entidade representada pelo SPrep ao governo se beneficia com a mudança administrativa proposta pelo então presidente Collor, por isso se configura como um Beneficiário da ação.

[29] Mudança dá novo perfil ao governo. (E-B-94-Jn-022)

Nas notícias analisadas, a maioria dos participantes do tipo Beneficiário foi representada por um grupo nominal denotando instituições governamentais, religiosas e empresariais, como governo, no exemplo anterior. Esse resultado, que representou o percentual de $71 \%$ do total de cláusulas com três participantes, indica que essas construções, no contexto analisado, codificam experiências da esfera pública, ou seja, de natureza mais coletiva.

Quanto à ordenação dos constituintes sintáticos, a frequência maior ocorreu com o SPrep codificado antes do objeto direto, corroborando o padrão sintático encontrado por Furtado da Cunha (2013). Em termos pragmáticos, a frequência da configuração SN SV SPrep SN aponta para o fato do Beneficiário ocupar um status mais proeminente e mais topicalizado na cláusula quando comparado ao objeto direto. 
Concernente à expansão por realce, as categorias circunstanciais de localização espacial e localização temporal foram as mais frequentes. A localização espacial é responsável por construir o desdobramento do processo no espaço (onde, de onde, aonde e para onde), como no exemplo seguinte, em que o sintagma adverbial na Itália situa a ação quanto ao lugar.

[30] Mohamed Ali Agca, 23 anos, entrou na Itália há duas semanas, vindo da Espanha, desembarcando em Milão. (E-B-94-Jn-012) Já a localização temporal é responsável por construir o desdobramento do processo no tempo. No fragmento [31] a seguir, a expressão este mês indica o momento em que o processo acontece.

[31] Caderneta dá 14,93\% este mês. (E-B-94-Jn-016)

O heatmap do parâmetro Expansão dos processos materiais (EXP), disponível na Figura 1H, mostra que os modos de expansão das cláusulas materiais ocorreram de forma relativamente pulverizada. Percebe-se, no entanto, uma concentração maior de construções sem qualquer tipo de elemento de expansão (representadas pelos neurônios azuis) na faixa que ocupa a parte mais inferior da figura, e uma concentração maior de cláusulas com expansão do tipo realce (representadas pelos neurônios verdes, amarelos e vermelhos) nas partes central e superior do referido mapa.

Nas notícias analisadas, a expansão por realce - especialmente a de localização espacial e a de localização temporal - foi a mais frequente, totalizando 71 ocorrências (o que corresponde a 54\% do total de cláusulas analisadas). Dada a natureza essencialmente narrativa das notícias jornalísticas, a expressiva presença das circunstâncias de localização nesse gênero discursivo justifica-se pela necessidade de situar os fatos relatados com relação ao tempo e ao lugar em que ocorreram.

Quando comparado a outros parâmetros, o parâmetro Expansão dos processos materiais (EXP) encontrou correlação maior com o parâmetro Processos materiais transitivos e intransitivos (TRI). Conforme se percebe na Tabela 1, exibida em seções anteriores, essa correlação atingiu o percentual de $-44 \%$, o que, em termos estatísticos, merece ser considerado.

Assim como aconteceu entre os parâmetros Natureza dos processos materiais (NAP) e Processos materiais transitivos e intransitivos (TRI), a correlação que se estabeleceu entre Expansão dos processos materiais (EXP) e Processos materiais transitivos e intransitivos (TRI) também foi negativa. Isso significa que, quando o valor de um parâmetro tende a subir, o valor do outro parâmetro tende a baixar. No caso dos parâmetros EXP e TRI, o percentual negativo pode ser interpretado a partir da análise comparativa entre os heatmaps que representam esses dois parâmetros (Figuras $1 \mathrm{H} \mathrm{e} \mathrm{1A),} \mathrm{que} \mathrm{permitem} \mathrm{vislumbrar} \mathrm{as} \mathrm{seguintes} \mathrm{tendências:}$

(i) Quando EXP é 1 (classe das cláusulas sem elementos de expansão, representada pelos neurônios azuis), TRI tende a ser 2 (classe das cláusulas transitivas, representada pelos neurônios vermelhos).

(ii) Quando EXP é 4 (classe das cláusulas de expansão por realce, representada pelos neurônios verde-claros), TRI tende a ser 1 (classe das cláusulas intransitivas, representada pelos neurônios azuis).

Essa correlação demonstra que, nos dados deste estudo, os elementos circunstanciais apareceram mais frequentemente nas cláusulas intransitivas. Em contrapartida, a maior parte das cláusulas transitivas não apresentou componentes circunstanciais. Em termos percentuais, 79\% das construções intransitivas apresentaram sintagmas adverbiais de lugar, tempo, modo e causa, e 63\% das construções transitivas não apresentaram nenhum tipo de expansão adverbial. Nas notícias jornalísticas, portanto, as construções intransitivas têm como objetivo informar quem fez o quê, onde, quando, como e por quê, ou o que aconteceu a, onde, quando, como e por quê ; as construções transitivas, por sua vez, têm como objetivo mais proeminente informar o que $x$ fez a $y$. Soma-se a isso o fato de, nas estruturas intransitivas, muitas vezes o elemento circunstancial ser inerente ao próprio processo - diferentemente do que acontece nas estruturas transitivas. Na cláusula em destaque no exemplo [30], anteriormente mencionado, o sintagma adverbial na Itália é intrínseco à ação, construída com o verbo entrar. 


\section{CONSIDERAÇÕES FINAIS}

Além dos modos de realização das cláusulas materiais nas notícias jornalísticas, os oito parâmetros descritivos, a metodologia de Mapas Auto-Organizáveis e as estimativas de correlação permitiram aferir, por exemplo, os seguintes aspectos:

(i) As mudanças que se destinam a um segundo participante (Meta) são, percentualmente, mais significativas que as mudanças confinadas ao próprio participante inerente (Ator). Essa preeminência quantitativa dos fazeres transitivos em relação aos fazeres intransitivos atesta que as experiências retratadas no contexto das notícias jornalísticas encontram maior correlação com a configuração o que $x$ fez a y.

(ii) As cláusulas materiais processuais (ou seja, aquelas que veiculam um acontecimento, e não um fazer, propriamente dito), em sua maioria, são expressões metafóricas do significado, cujo participante Ator resguarda indícios de um participante do tipo Meta. Nesse tipo de expressão, o jornalista busca enfatizar o aspecto causa-e-efeito da mudança, em detrimento ao aspecto ação-e-extensão.

(iii) Apesar da representativa frequência do Ator/Sujeito nas funções de agente híbrido, de causa e de paciente, a função numericamente mais expressiva desse participante foi a de agente prototípico, ou seja, de uma entidade [+humana e +individualizada]. Esse tipo de configuração aponta para a intencionalidade das notícias jornalísticas de expor o indivíduo responsável pela mudança.

(iv) Nesse contexto sociocomunicativo, as expressões mais congruentes do significado cumprem a função de identificar os responsáveis pelo desenrolar do processo. Em oposição a esse objetivo pragmático-discursivo, as expressões metafóricas, em sua maioria, cumprem a função de ocultar a entidade agentiva, sem que com isso sejam geradas proposições incompletas.

Para finalizar, reiteramos que os resultados encontrados estabelecem estreita relação com os contextos comunicativo e sóciohistórico em que os textos são produzidos. Estudos complementares, de notícias pertencentes a períodos históricos distintos, revelam, por exemplo, significativa diferença quanto ao uso das construções metafóricas em que o Ator resguarda propriedades circunstanciais e das construções metonímicas do tipo Instituição pelos responsáveis: se no início do século XIX essas codificações ainda não apareciam de forma expressiva, notícias mais recentes apontam para o inverso, ou seja, para o fato dos jornalistas cada vez mais lançarem mão desses recursos linguísticos como importantes estratégias discursivas (DAMASCENO et al., 2014). A maior recorrência dessas codificações encontra-se em consonância com as transformações da sociedade ao longo dos anos, como a sistematização e a legitimação das instituições públicas e privadas e, como consequência, as responsabilidades atribuídas a essas corporações. Assim, apesar de considerarmos que as análises exibidas aqui contribuem para a ampliação do estudo da transitividade, especialmente por se pautarem em critérios sintáticos, semânticos e pragmático-discursivos, acusamos a necessidade de continuidade da pesquisa, principalmente no que tange à diversificação quanto ao gênero discursivo e ao período de elaboração dos textos, a fim de que as mudanças dos padrões linguísticos, em razão das intenções comunicativas e das transformações sociais, sejam mais eficazmente contempladas.

\section{REFERÊNCIAS}

BORBA, F. S. Uma gramática de valências para o português. São Paulo: Ática, 1996.

CANÇADO, M. Manual de semântica: noções básicas e exercícios. São Paulo: Contexto, 2013.

CHAFE, W. Significado e estrutura linguística. Trad. Maria Helena de Moura Neves et. al. Rio de Janeiro: Livros técnicos e científicos, 1979.

Damasceno \& Rodrigues | Os processos materiais em notícias jornalísticas: seleção de parâmetros descritivos. 
DAMASCENO, G. L. N.; RODRIGUES, V. V.; NOBRE, M. M. R. A metáfora da transitividade no gênero notícia jornalística: uma abordagem sistêmico-funcional. Revista Signótica, v. 26, n. 2, p. 495-517, 2014.

DAMASCENO, G. L. N. A transitividade de processos materiais em notícias jornalísticas. 2016. Tese (Doutorado em Letras Vernáculas) - Faculdade de Letras, Universidade Federal do Rio de Janeiro, Rio de Janeiro.

FILMORE, C. J. The case for case. In: BACH, E.; HARMS, R. (Ed.). Universals in linguistic theory. New York: Holt, Rinnehart and Winston, 1968. p. 1-88.

FURTADO DA CUNHA, M. A. Polissemia construcional e convencionalização: o caso da construção ditransitiva. Revista do GEL, São Paulo, v. 10, n. 2, p. 77-99, 2013.

GIVÓN, T. Syntax - a functional typological introduction. v. 1. Amsterdam: John Benjamins, 1984.

HALLIDAY, M. A. K. An introduction to functional grammar. 2. ed. London: Edward Arnold, 1994.

; MATTHIESSEN, C. M. I. M. An introduction to functional grammar. 3. ed. London: Arnold, 2004.

HAYKIN, S. Redes neurais: princípios e prática. 2. ed. Bookman Companhia, 2001.

HINTZE, A. C. J. Contribuições de pressupostos básicos do funcionalismo para análise de textos do gênero notícia nos meios impresso, televisivo e on line. In: ANTONIO, J. D.; NAVARRO, P. (Org.). O texto como objeto de ensino, de descrição linguística e de análise textual e discursiva. Maringá: UEM, 2009. p. 81-95.

HOPPER, P.; THOMPSON, S. Transitivity in grammar and discourse. Language, Washington, v. 56, n. 2, p. 251-299, 1980.

KOHONEN, T. Self-organized formation of topologically correct feature maps. Biological Cybernetics, n. 43, p. 59-69, 1982.

LAKOFF, G.; JOHNSON, M. Metáforas de la vida cotidiana. Trad. Carmen González Marín. 7. ed. Madri: Catedra, 2007.

PEZATTI, E. G. A ordem de palavras e o caráter nominativo/ergativo do português falado. Revista Alfa, São Paulo, v. 37, n. 1, p. 159$178,1993$.

R DEVELOPMENT CORE TEAM. R: A language and environment for statistical computing. R Foundation for Statistical Computing, Vienna, Austria, 2011. Disponível em: <http://www.r-project.org > Acesso em: 08 nov. 2015.

RAPOSO, E. B. P. et al. (Org.). Gramática do português. Lisboa: Fundação Calouste Gulbenkian, 2013.

Fórum linguistic., Florianópolis, v. 14, n.2, p.2096-2115, abr./jun.2017. 
RADDEN, G.; KÖVECSES, Z. Towards a theory of metonymy. In: PANTHER, K. U.; RADDEN, G. (Ed.). Metonymy in language and thought. Philadelphia: John Benjamins, 1999. p. 17-59.

STEEL, R. G. D.; TORRIE, J. H. Principles and procedures of statistics: a biometrical approach. 2. ed. New York: McGraw-Hill Book Company, 1980.

THOMPSON, G. Introducing functional grammar. London: Edward Arnold, 1996.

WEHRENS, R.; BUYDENS, L. M. C. Self- and Super-organizing Maps in R: The kohonen Package. Journal of Statistical Software, v. 21, n. 5, p. 1-19, 2007. 